\title{
Growth of Hexagonal AIN Crystalline Microrod by Physical Vapor Transport Method
}

\author{
WANG Hua-Jie ${ }^{1,2}$, LIU Xue-Chao ${ }^{1}$, KONG Hai-Kuan ${ }^{1}$, XIN Jun ${ }^{1}$, GAO Pan ${ }^{1}$, ZHUO Shi-Yi ${ }^{1}$, SHI Er-Wei ${ }^{1}$ \\ (1. Shanghai Institute of Ceramics, Chinese Academy of Sciences, Shanghai 201800, China; 2. University of Chinese Academy of \\ Sciences, Beijing 100049, China)
}

\begin{abstract}
Hexagonal aluminium nitride (AIN) microrods with high crystalline quality were grown by physical vapor transport (PVT) method at low growth temperature between 1700 and $1850^{\circ} \mathrm{C}$. The length of as-grown microrod is around $1 \mathrm{~cm}$, and the width between 200-400 $\mu \mathrm{m}$. The microrod exhibits typical hexagonal geometrical shape with pale yellow color under optical microscopy. Scanning electron microscope (SEM) and atomic force microscope (AFM) images show each microrod with closely arranged step waviness, of which the step interval is $2-4 \mu \mathrm{m}$ and the height several nanometers. Raman spectrum characterization showed characteristic peaks of high crystalline AlN. The rod-like structure is attributed to slow growth velocity at lower crystalline temperature, enabling $\mathrm{Al}$ and $\mathrm{N}$ atoms having enough time to move to the lower energy site and to form hexagonal microrod along $<0001>$ direction. High quality hexagonal AIN microrod is an enrichment to one-dimensional semiconductor materials. Data from this study suggest that, by further study on size and impurity control, high performance miniaturized opto-electronic device is hopeful to be achieved.
\end{abstract}

Key words: III-V semiconductors; aluminum nitride; hexagonal microrod; physical vapor transport

Micro-nano scale semiconductor has gained extensive interest due to their potential application in optoelectronic and electronic devices. By employing micro-nano scale material, device structure can be efficiently minimized. High compactness and light weight properties are therefore hopeful to be realized. Aluminium nitride (AlN) crystal is a typical III-V semiconductor material with a direct bandgap up to $6.2 \mathrm{eV}$, and has a high thermal conductivity $319 \mathrm{~W} /(\mathrm{m} \cdot \mathrm{K})^{[1]}$. It is regarded as one of the most promising semiconductor materials for fabricating ultraviolet optoelectronic devices like light-emitting diode and laser diode. Moreover, the large bandgap and high thermal conductivity show good potential in high power electronic devices. Physical vapor transport (PVT) is a conventional method for growing single crystal $\mathrm{AlN}^{[2]}$. It has comparatively higher growth velocity and can obtain a better crystal quality. In the PVT experiments, it's found that large quantity of rod-like AlN crystal is grown at a lower crystalline temperature. AlN microrod is an enrichment to the family of one-dimensional micro-nano materials ${ }^{[3]}$.

One-dimensional AlN has been synthesized by methods like chemical vapor deposition ${ }^{[4]}$, carbo-thermal reaction ${ }^{[5-6]}$, and sublimation method ${ }^{[7-8]}$. A diversity of different shapes like threaded ${ }^{[8]}$, hexagonal ${ }^{[9]}$, triangular ${ }^{[10]}$ structure have been observed. The size of reported one-dimensional structure AlN is from tens of nanometers to tens of micrometers. The AlN rod grown in our experiment is $200-400 \mu \mathrm{m}$ in width and around $1 \mathrm{~cm}$ for length, which is the largest size of reported one-dimensional $\mathrm{AlN}^{[8,10-11]}$. Besides, the grown AlN microrod exhibits a typical hexagonal geometrical shape in consistent with the single crystal structure of bulk AlN and shows high crystalline quality. So it should be valuable to take a research on its growth and characterization.

In this paper, PVT method is used to grow rod-like AIN by controlling the crystalline temperature at a relatively low value in order to avoid the growth of bulk AlN. The rod-like AIN is characterized by different techniques and the one-dimensional anisotropic growth mechanism is discussed.

\section{Experimental}

Figure 1 showed the schematic diagram of PVT growth hotzone for growing AlN microrod. A double crucible

Received date: 2016-04-13; Modified date: 2016-05-04

Foundation item: National High-tech R\&D program of China (863 Program, 2014AA032602); National Key R\&D program (2016YFB0400400) Shanghai Engineering Research Center of Single Crystal Silicon Carbide

Biography: WANG Hua-Jie(1992-), male, candidate of master degree. E-mail: wanghj.mail@foxmail.com

Corresponding author: LIU Xue-Chao, associate professor. E-mail: xcliu@mail.sic.ac.cn 


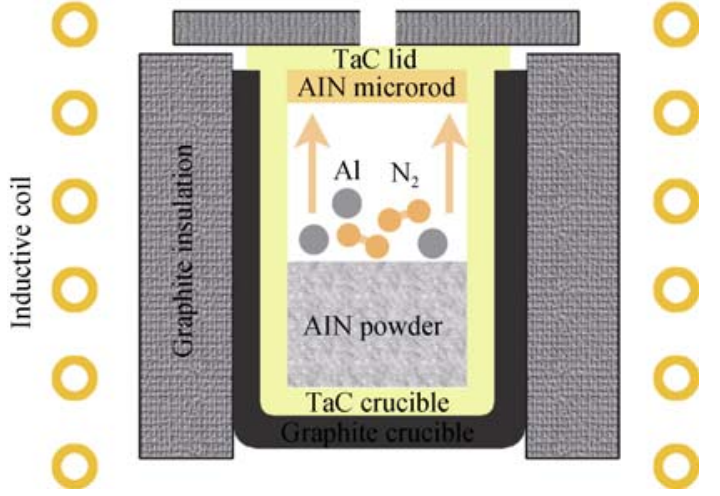

Fig. 1 Schematic diagram of PVT growth system for AlN microrod

structure (with the carbonized Ta crucible inside a graphite crucible) combined with inductive coil was used. The TaC crucible was mainly to prevent the influence of carbon impurity. High purity AIN (99.9\%) powders were put at the bottom of $\mathrm{TaC}$ crucible. The $\mathrm{TaC}$ crucible was $105 \mathrm{~mm}$ in height and $49 \mathrm{~mm}$ in diameter. The thickness of the side and bottom wall was $2 \mathrm{~mm}$. We used around $100 \mathrm{~g}$ AlN powder each time. The distance between source and lid was around $35 \mathrm{~mm}$. The thermal insulating material was graphite felt. A top hole was designed to create low crystallization temperature. The vertical temperature gradient can be precisely controlled by manipulating both the thickness of graphite felt and the relative position between crucible and inductive coil. Infrared thermometer was used to monitor the temperature at the top $\mathrm{TaC}$ lid. The growth temperature was set at $1700-1850^{\circ} \mathrm{C}$ with the nitrogen pressure of $699 \mathrm{~Pa}$ The AlN powders were sublimated and recrystallized into crystalline state with a growth time of $35 \mathrm{~h}$.

Optical microscopy, scanning electron microscope (SEM) and atom force microscope (AFM) were used to investigate the surface morphology of as-grown AlN microrod. The element distribution was analyzed by energy dispersive spectrometer (EDS) attached on SEM equipment. The crystal structure was characterized by Raman spectrometer with a $325 \mathrm{~nm}$ ultraviolet laser.

\section{Results and Discussion}

Figure 2 shows the images of as-grown AlN microrod. By adjusting the thickness of graphite felt and the relative position between crucible and inductive coil, AIN microrods grow on the top raw material powder zone (Fig. 2(a)) or the bottom of crucible lid (Fig. 2(b)). The TaC lid in the Fig. 2(b) is $55 \mathrm{~mm}$ in diameter. A large number of rodlike AIN cluster together in the crucible. The white wadding in the Fig. 2(b) is the source powder. There are some rod formed on the powder area. When the lid is taken out, these source powder area is also peeled off. The

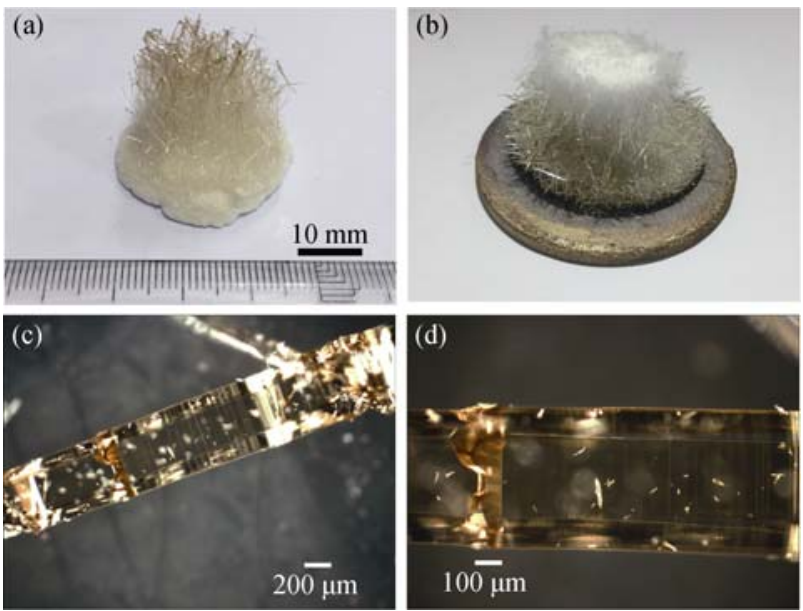

Fig. 2 Images of AlN microrod

(a) Growth on the top raw material; (b) Growth on the bottom of TaC lid; (c - d) Dark-field image taken by optical microscopy

length of prismatic rods is around $1 \mathrm{~cm}$. The width of each microrod edge plane is $200-400 \mu \mathrm{m}$. As shown in Fig. 2(c) and 2(d), the AlN microrod is transparent with pale yellow color when characterized by optical microscopy with dark-field mode. The natural AIN crystal should be colorless. It's supposed the yellowish color should be caused by carbon impurity which comes from the graphite crucible, carbon felt and source powder.

SEM images in Fig. 3(a) show that AIN microrod exhibits a typical hexagonal geometrical shape, which is in consistent with the single crystal structure of bulk AIN. The sample prismatic side faces should be planes $\{10 \overline{10}\}$ along $<0001>$ direction $^{[9]}$. Clear step waviness can be seen by further magnifying the SEM image as shown in Fig. 3(b).

AFM characterization is performed on the surface of a single AlN microrod. It can be seen that the step interval is 2-4 $\mu \mathrm{m}$, while the step height is around several nanometers as shown in Fig. 4(b) and Fig 4(d). These steps indicate that the AlN is grown in a step-flow mode, which is conducive to obtain better crystal quality. Table 1 shows the EDS elemental results which confirms the existence of carbon impurity in AlN microrod. O element is kind of common impurity in AlN crystal. But it's not
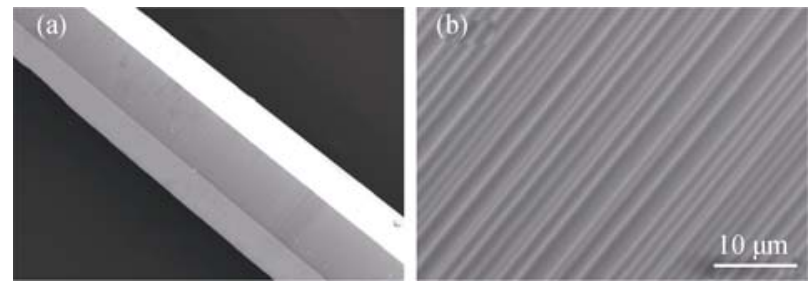

Fig. 3 SEM images of AIN microrod

(a) Low magnification image; (b) High magnification image with clear step waviness on the microrod surface 
(a)

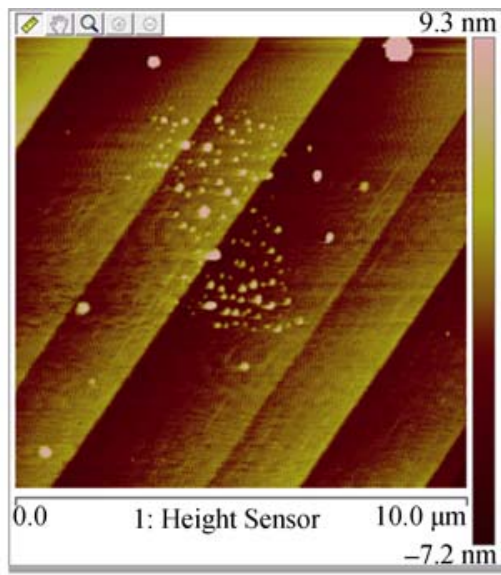

(c)

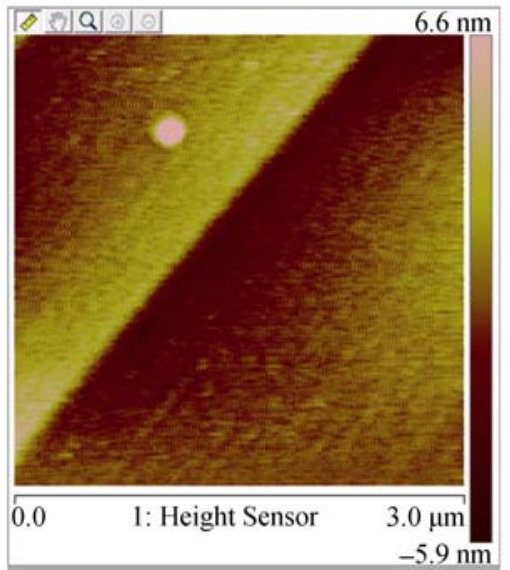

(b)

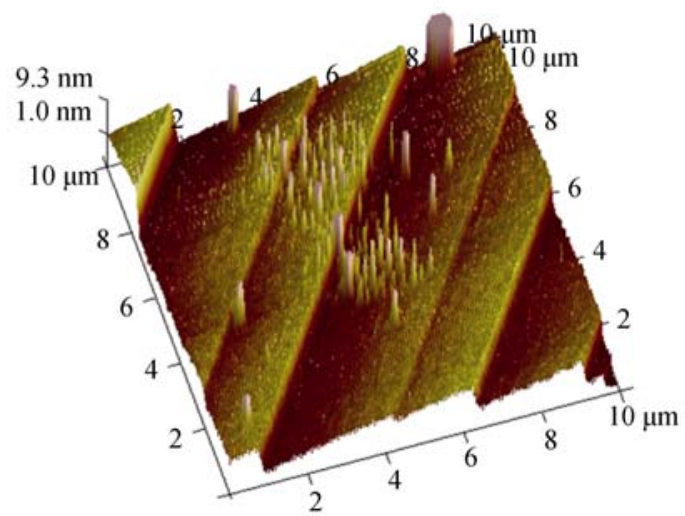

(d)

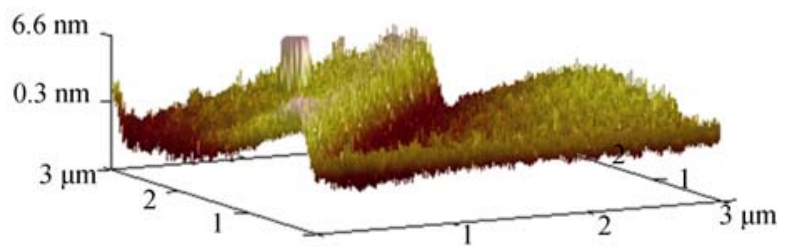

Fig. 4 AFM images of AlN microrod

(a, c) AFM surface morphology on the AIN microrod side face; (b, d) Three dimensional AFM image

tested out in EDS result. It's considered the accuracy of EDS is poor for light element; and the $\mathrm{O}$ concentration is truly low compared to other impurity element.

Figure 5 shows the Raman spectrum of AlN microrod. Five peaks corresponding to $\mathrm{A}_{1}(\mathrm{TO}), \mathrm{E}_{2}(\mathrm{High})$, $\mathrm{E}_{1}(\mathrm{TO}), \mathrm{A}_{1}(\mathrm{LO})$ and $\mathrm{E}_{1}(\mathrm{LO})$ modes of wurtzite structure $\mathrm{AlN}^{[12]}$ are clearly observed. Raman spectrum is an effective method to evaluate crystal structure and quality. The value of FWHM (Full Width at Half Maximum) for each Raman peak can be calculated through Gauss fitting each peak. The FWHM value of $\mathrm{E}_{2}(\mathrm{High})$ mode is around $10 \mathrm{~cm}^{-1}$, which indicates a good crystalline quality of AIN microrod ${ }^{[13-14]}$.

As for the growth mechanism of AlN microrod at the top of raw material powder and at the bottom of crucible lid by PVT method, it is mainly caused by the difference

Table 1 Elemental analysis of AIN microrod measured by EDS

\begin{tabular}{ccc}
\hline Element & Atomic/at $\%$ & Concentration $/ \mathrm{wt} \%$ \\
\hline $\mathrm{C}$ & 4.296 & 2.383 \\
$\mathrm{~N}$ & 36.089 & 23.342 \\
$\mathrm{Al}$ & 59.592 & 74.246 \\
$\mathrm{Si}$ & 0.023 & 0.030 \\
Total & 100.000 & 100.000 \\
\hline
\end{tabular}

in vertical temperature gradient. The AlN powders located at the bottom of crucible decompose into vapor phase of $\mathrm{Al}$ and $\mathrm{N}_{2}$ at a high temperature and proper pressure as shown in Eq. (1). The decomposed $\mathrm{Al}$ vapor and nitrogen react with each other and form rod-like structure at the surface of AIN powders. While driven by a proper vertical temperature gradient, $\mathrm{N}_{2}$ and $\mathrm{Al}$ transport to the crucible lid, and then react with each other and recrystallize to be rod-like structure at the bottom of crucible lid.

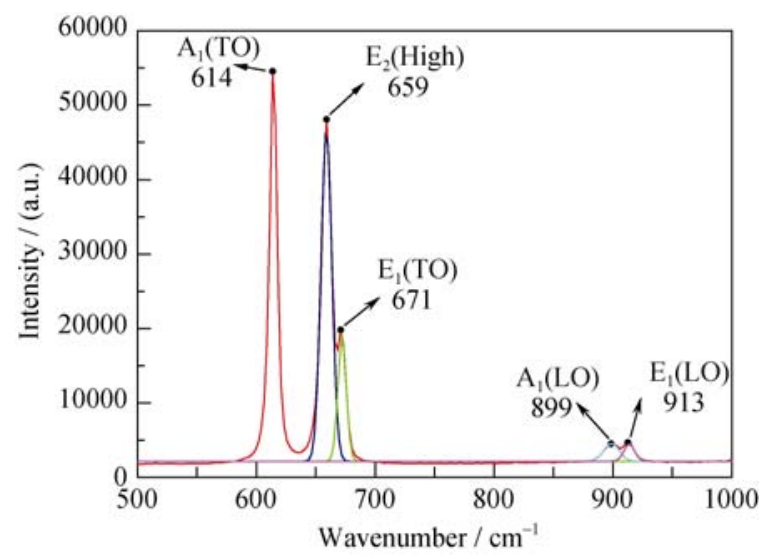

Fig. 5 Raman spectrum of AlN microrod 


$$
\mathrm{AlN}(\mathrm{s}) \rightleftharpoons \mathrm{Al}(\mathrm{g})+\frac{1}{2} \mathrm{~N}_{2}(\mathrm{~g})
$$

The top lid temperature can be precisely adjusted and controlled by the thickness of graphite felt and the relative position between the crucible and the inductive coil. At a relatively low crystallized temperature, the reaction between $\mathrm{Al}$ vapor and nitrogen is very slow. $\mathrm{Al}$ and $\mathrm{N}$ atoms have enough time to deposit and diffuse to the lowest energy site ${ }^{[15]}$. Deposition along $c$-axis has a lower energy, which leads to the one-dimensional anisotropic growth of AlN microrod.

\section{Conclusion}

Hexagonal AIN microrods with a high crystalline quality have been grown by PVT method. The width of each AIN microrod is about hundreds of microns. The SEM and AFM images show closely arranged step waviness on each microrod edge plane. The AlN microrod shows transparent property with yellowish color, which is supposed to be caused by carbon impurity. The growth mechanism of rod-like structural AIN is attributed to slow growth velocity at a low temperature, which makes $\mathrm{Al}$ and $\mathrm{N}$ atoms have enough time to move to the lower energy site. High quality hexagonal AIN microrod is an enrichment to one-dimensional AIN material. By doping $\mathrm{Si}, \mathrm{Mg}$ or other impurity to form n-type or p-type semiconductor and metal deposition, high performance miniaturized optoelectronic device is hopeful to be achieved. Thus, it is worth of further study on the growth control and electrical properties of AIN microrod.

\section{References:}

[1] SLACK G A, TANZILLI R A, POHL R O, et al. The intrinsic thermal conductivity of AIN. J. Phys. Chem. Solids, 1987, 48(7): 641-647.

[2] DALMAU R, SITAR Z. AlN Bulk Crystal Growth by Physical Vapor Transport //Dhanaraj G, Byrappa K, Prasad V, et al. Springer Handbook of Crystal Growth. Springer Berlin Heidelberg. 2010: 821-843.

[3] KENRY, YONG K T, YU S F. AlN nanowires: synthesis, physical properties, and nanoelectronics applications. Journal of Materials Science, 2012, 47(14): 5341-5360.

[4] JIE Z, YUAN Y, BO Y, et al. [0001] oriented aluminum nitride one-dimensional nanostructures: synthesis, structure evolution, and electrical properties. ACS Nano, 2008, 2(1): 134-142.

[5] MIAO W G, WU Y, ZHOU H P. Morphologies and orientations of aluminum nitride whiskers. Journal of Inorganic Materials, 1997, 12(3): 425-429.

[6] ZHOU H, CHEN H, WU Y, et al. Structure characteristics of AlN whiskers fabricated by the carbo-thermal reduction method. Journal of Materials Science, 1998, 33(16): 4249-4253.

[7] ZHOU H P, CHEN H, LIU Y C, et al. Fabricaion process and growth characteristics of AIN whiskers by sublimation- recrystallization method. Journal of Inorganic Materials, 1998, 13(4): 477-483.

[8] WANG J, ZHAO M, ZUO S B, et al. Growth of threaded AIN whiskers by a physical vapor transport metho. Chinese Physics $B$, 2014, 23(8): 088103.

[9] BAO H Q, CHEN X L, LI H, et al. The sublimation growth of AIN fibers: transformations in morphology \& fiber direction. Applied Physics A, 2008, 94(1): 173-177.

[10] JIANG L, ZUO S, WANG W, et al. Role of Ni in the controlled growth of single crystal AlN triangular microfibers: Morphology evolvement, growth kinetics and photoluminescence. Journal of Crystal Growth, 2011, 318(1): 1089-1094.

[11] YAZDI G R, SYVÄJÄRVI M, YAKIMOVA R. Formation of needle-like and columnar structures of AIN. Journal of Crystal Growth, 2007, 300(1): 130-135.

[12] DAVYDOV V Y, KITAEV Y E, GONCHARUK I N, et al. Phonon dispersion and Raman scattering in hexagonal GaN and AlN. Phys. Rev. B, 1998, 58(19): 12899-12907.

[13] SUMATHI R R. Bulk AlN single crystal growth on foreign substrate and preparation of free-standing native seeds. CrystEngComm, 2013, 15(12): 2232-2240.

[14] LIU M S, NUGENT K W, PRAWER S, et al. Micro-Raman scattering properties of highly oriented AlN films. Int. J. Mod. Phys. B, 1998, 12(19): 1963-1974.

[15] WU B, MA R, ZHANG H, et al. Modeling and simulation of AlN bulk sublimation growth systems. Journal of Crystal Growth, 2004, 266(1/2/3): 303-312.

\title{
物理气相输运法生长 AIN 六方微晶柱
}

\author{
王华杰 ${ }^{1,2}$, 刘学超 ${ }^{1}$, 孔海宽 ${ }^{1}$, 忻 隽 $^{1}$, 高 攀 $^{1}$, 卓世异 ${ }^{1}$, 施尔畏 ${ }^{1}$
}

(1. 中国科学院 上海硅酸盐研究所, 上海 201800;2. 中国科学院大学, 北京 100049)

\begin{abstract}
摘 要: 采用物理气相输运法(Physical Vapor Transport, PVT), 在 $1700 \sim 1850^{\circ} \mathrm{C}$ 生长温度下制备出 $\mathrm{AlN}$ 六方微晶柱; 晶 柱长度在 $1 \mathrm{~cm}$ 左右, 宽度在 $200 \sim 400 \mu \mathrm{m}$, 光学显微镜下观察为六棱柱形状并呈透明浅黄色光泽; 扫描电子显微镜和 原子力显微镜测试表明: $\mathrm{AlN}$ 晶柱表面为整齐台阶状形貌，台阶宽度为 $2 \sim 4 \mu \mathrm{m}$ ，高度在几个纳米; 拉曼光谱测试 $\mathrm{AlN}$ 晶柱具有良好结晶质量。PVT 法生长 AlN 六方微晶柱主要是在偏低温度下 AlN 晶体生长速率较慢, Al 原子和 $\mathrm{N}$ 原子 有足够时间迁移到能量较低位置结晶生长, 进而沿着 $<0001>$ 方向形成柱状结构。AlN 六方微晶柱是对一维半导体材料 领域的补充, 通过对晶柱尺寸及杂质控制的进一步研究, 有望在微型光电器件领域表现出应用价值。
\end{abstract}

关 键 词: III-V 族半导体; 氮化铝(AIN)晶体; 六方微米柱; 物理气相输运(PVT)

中图分类号: $\mathrm{O} 78$

文献标识码: A 